E3S Web of Conferences 1, 16007 (2013)

DOI: $10.1051 / \mathrm{e} 3$ sconf/20130116007

(c) Owned by the authors, published by EDP Sciences, 2013

\title{
Acidic extraction and precipitation of heavy metals from biomass incinerator cyclone fly ash
}

\author{
M. Kröppl ${ }^{1}$ and C. Lanzerstorfer ${ }^{1}$ \\ ${ }^{1}$ Upper Austrian University of Applied Sciences, Campus Wels, 4600 Wels, AUSTRIA, m.kroeppl@fh-wels.at and \\ c.lanzerstorfer@fh-wels.at
}

\begin{abstract}
Biomass incineration is increasingly used for the generation of heat and/or electricity. After incineration two ash fractions remain. Bottom ashes (the coarser ash fraction) can usually be used as fertilizing agent on fields as it contains valuable elements for soils and plants and only minor concentrations of heavy metals. Fly ashes (the finer ash fraction) are in most cases disposed as their heavy metal concentrations are too high for a usage as soil enhancer. In this study highly heavy metal contaminated fly ash has been cleaned through extraction with hydrochloric acid. The heavy metals were removed from the extract by precipitation with sodium hydroxide. After the cleaning procedure the ash can be pelletized and be returned to the soils.
\end{abstract}

Key words: heavy metals, biomass incineration, fly ashes, extraction

\section{Introduction}

Biomass incineration is increasingly used for the generation of heat and/or electricity. Mostly wood in form of wood chips, pellets or bark is burned, but also other biomass (e.g. straw) can be used as fuel for incineration.

Biomass is a good alternative to fossil fuels. Due to its $\mathrm{CO}_{2}$-neutrality (hereby not taking into account gas emissions produced by the production of wood (cutting of wood, transport, ...)) [Chau et al, 2009] and because of its natural renewability, the number of biomass incinerators has risen in the last years. Especially wood seems a good choice as biomass in terms of efficiency and $\mathrm{CO}_{2}$ abatement [Bram et al, 2009].

In Upper Austria 10,000 to 25,000 t of ashes are produced from biomass incineration ever year. From this amount 20 to 30 percent account to the fly ash fraction [OÖ Biomasseverband].

During the incineration process the organic input material is decomposed - the only remains after incineration are ashes which are collected at the bottom of the incinerator (bottom ashes) or in a one or two stage gas cleaning system (fly ashes). The ashes contain valuable nutritive elements for plants and soils. In higher amounts calcium, potassium, magnesium and phosphorus can be found [Pöykio et al, 2008]. Returning the ashes to the soil would therefore be the best recycling way to bring back the nutrients and close the element-cycles. It is further known that biomass ashes are very alkaline $(\mathrm{pH}$ above 12 when mixing with water) [Pöykio et al, 2008]. Therefore ashes can also be a good soil additive for enhancing the $\mathrm{pH}$ of acid soils.

Besides soil enhancing elements, also heavy metals are found in the ashes - especially the fly ashes often show higher concentrations of these elements. Heavy metals can be harmful for animals and men. Especially via the food chain they can cause toxic effects already in very low concentrations. Thus, their concentrations in the biomass ashes have to be below certain limit concentrations so that the biomass ashes can be used as soil enhancers on fields. Table 1 shows the limit concentrations for heavy metals in biomass ashes in Austria.

Table 1. Limit concentrations for heavy metals given for the use of plant-ashes on crop- and farmland [Austrian Ministry of Agriculture, 2011]

\begin{tabular}{|c|c|c|c|}
\hline elements & $\begin{array}{c}\text { limits } \\
{[\mathrm{mg} / \mathrm{kg}]}\end{array}$ & elements & $\begin{array}{c}\text { limits } \\
{[\mathrm{mg} / \mathrm{kg}]}\end{array}$ \\
\hline $\mathrm{Zn}$ & 1,500 & $\mathrm{Ni}$ & 200 \\
\hline $\mathrm{Cu}$ & 250 & $\mathrm{As}$ & 20 \\
\hline $\mathrm{Cr}$ & 250 & $\mathrm{Cd}$ & 8 \\
\hline $\mathrm{Pb}$ & 200 & & \\
\hline
\end{tabular}

Concentrations of heavy metals in bottom ashes are usually below the listed concentration limits which allow their return to the soils. Fly ashes, though, often exceed 
the limit values at least for some elements. Therefore, currently, fly ashes have to be disposed off in landfill sites and cannot be used as fertilizing agents on soils. Simple methods for the reduction of the heavy metal concentrations in the ashes below the limit values could help to increase the amount of ash recycled to the soil.

It is well known that heavy metals have increased mobility at low $\mathrm{pH}$. Leaching biomass fly ashes with acids could therefore be used as cleaning method.

The aim of this study was the determination of the possibility to clean the fly ashes of a typical biomass incinerator by acid leaching. The ash fractions for all experiments were drawn from an Upper Austrian municipal district heating plant.

As the heavy metal concentrations in the bottom ash was below the Austrian limit values for use on fields, only fly ash was considered for leaching experiments. The cyclone fly ash accounted for around $20 \%$ of the total ash mass and $80 \%$ of the fly ash fraction the focus was layed on the cleaning of the cyclone fly ash fraction through acid leaching with hydrochloric acid. The leached fly ash was then separated from the leachate by vacuum filtration and subsequently dried and pelletized. For precipitation of the heavy metals in the leachate with $\mathrm{NaOH}$ a pH-range from 8 to 12.5 was investigated.

Heavy metal concentrations were determined in the ashes, the leachates after the acidic extraction and the solutions after precipitation with sodium hydroxide.

\section{Materials and Methods}

In the present study fly ash from an Upper Austrian biomass incinerator ( $5 \mathrm{MW}$ ) was used for all experiments. The ash has been produced through wood incineration and has been collected in the two stage gas cleaning system $\left(1^{\text {st }}\right.$ stage: cyclone, $2^{\text {nd }}$ stage: electrostatic precipitator). The mass ratios of the three ash fractions are approximately $75 \%$ coarse ash, $20 \%$ cyclone fly ash and $5 \%$ fly ash from the electrostatic precipitator.

The fly ashes were brought into solution with microwave acidic digestion (StarT, MLS Laborsysteme $\mathrm{GmbH})$ using $2 \mathrm{ml} \mathrm{HNO}_{3}(65 \%)$ and $6 \mathrm{ml} \mathrm{HCl} \mathrm{(35 \% )} \mathrm{for}$ $0.2 \mathrm{~g}$ of ashes. The digestion temperature was $200^{\circ} \mathrm{C}$. All analyzes were done in duplicate.

Table 2. Chemicals, reagents and purpose for its usage.

\begin{tabular}{|c|c|}
\hline reagent & description, company \\
\hline fly ash & $\begin{array}{c}\text { from a biomass incineration } \\
\text { plant (wood inc.) }\end{array}$ \\
\hline $\mathrm{HCl}$ & $35 \%$, p.a., Merck \\
\hline $\mathrm{HNO}_{3}$ & $65 \%$, p.a., Merck \\
\hline $\begin{array}{c}\text { Multistandard } \\
\text { CertiPUR IV }\end{array}$ & $\begin{array}{c}1,000 \mathrm{mg} / \mathrm{L}, \text { for } \mathrm{Cd}, \mathrm{Co}, \mathrm{Cr}, \mathrm{Cu}, \\
\mathrm{K}, \mathrm{Mg}, \mathrm{Mn}, \mathrm{Ni}, \mathrm{Pb} \text { and } \mathrm{Zn} \\
\text { Merck }\end{array}$ \\
\hline $\begin{array}{c}\text { Single-element } \\
\text { standard }\end{array}$ & $1,000 \mathrm{mg} / \mathrm{L}$, for As, Merck \\
\hline $\mathrm{Ar}$ & 5.0, Messer Austria \\
\hline $\mathrm{NaOH}^{\mathrm{H}} \mathrm{O}$ & d M \\
\hline
\end{tabular}

The procedure for the digestion and determination of the heavy metals in the fly ashes has already been validated previously [Kröppl, Zeiner, Lanzerstorfer, 2008].

As inductively coupled plasma-optical emission spectroscopy is a good choice for determining different metal concentrations in a short time and at trace level concentrations, as analytical instrument an ICP-OES (Horiba Jobin Yvon, Ultima 2) was used for the quantitative analyzes of the heavy metal concentrations.

Table 2 gives all chemicals and reagents used in this study.

\section{Extraction procedure}

For the acidic extraction and the mobilization of the heavy metals, $\mathrm{pH}$ between 4 and 6 was adjusted with $\mathrm{HCl}$ (37\%). A solid-to-liquid-ratio of 1:5 and 1:10 was tested. After adjusting the $\mathrm{pH}$, the suspensions were stirred for 0.5 or 1 hour. All experiments (with different $\mathrm{pH}$, different solid-to-liquid-ratio and different extraction time) have been set up twice in order to increase the experimental preciseness.

After the extraction the ashes were separated from the leachates through vacuum filtration. The heavy metal content in the leachates was determined with ICP-OES.

\section{Precipitation of heavy metals}

For elimination of the heavy metals in the leachates, a sodium hydroxide solution (4 M) was used for the formation of metal hydroxides at $\mathrm{pH}$ values between 8 and 12.5 .

The precipitated metal hydroxides were separated through a fluted filter. The heavy metal content in the remaining solutions has been evaluated with ICP-OES.

\section{Results and Discussion}

Table 3 gives the concentrations of the heavy metals in the three ash fractions of the biomass incinerator. It can be seen that in the coarse ash fraction the concentration of Arsenic is in the range of the limit, all other heavy metals are well below the limits. In the fly ash fraction from the cyclone the concentrations of Zinc, Arsenic and Cadmium are above the limit values. The fly ash from the electrostatic precipitator is even more polluted with heavy metals. Here, Zinc, Arsenic, Cadmium and Lead are present in higher concentrations than the allowed limits for returning the ashes to the soil.

As the cyclone fly ash fraction accounts to around $80 \%$ of mass of the fly ash fraction, the focus was layed on cleaning this fly ash fraction.

Using as design value for the leaching the Cadmium concentration in the cyclone fly ash as the mean plus one standard deviation $(27 \mathrm{mg} / \mathrm{kg})$, a reduction of $70 \%$ of the Cadmium concentration is required in order to reach the limit concentration of $8 \mathrm{mg} / \mathrm{kg}$. For the concentration of Arsenic and Zinc the necessary reduction is $40 \%$ and $16 \%$, respectively. In a previous study [Kröppl, Ceras-Arrese, Lanzerstorfer, 2011] it was found that for a $70 \%$-reduction of the Cadmium concentration a $\mathrm{pH}$ 
below 6 is necessary. Therefore in this study the $\mathrm{pH}$-range between 4 and 6 was investigated.

Table 3. Heavy metal concentrations in the ash fractions of the biomass incinerator

\begin{tabular}{|c|c|c|c|}
\hline elements & $\begin{array}{c}\text { coarse } \\
\text { ash } \\
{[\mathrm{mg} / \mathrm{kg}]}\end{array}$ & \multicolumn{2}{|c|}{ fly ash $[\mathrm{mg} / \mathrm{kg}]$} \\
\cline { 3 - 4 } & $\begin{array}{c}254 \\
\pm 90.0\end{array}$ & 1,790 & 11,200 \\
$\mathrm{Zn}$ & 92.7 & 125 & $\pm 3,820$ \\
\hline $\mathrm{Cu}$ & \pm 9.55 & \pm 26.5 & $\begin{array}{c}221 \\
\pm 50.6\end{array}$ \\
\hline $\mathrm{Cr}$ & 40.2 & 73.2 & 75 \\
& \pm 8.34 & \pm 11.4 & \pm 4.41 \\
\hline $\mathrm{Pb}$ & $<15$ & 54.8 & 368 \\
& & \pm 19.5 & \pm 147 \\
\hline $\mathrm{Ni}$ & 34.3 & 34.2 & 15.6 \\
& \pm 17.5 & \pm 0.91 & \pm 4.03 \\
\hline $\mathrm{As}$ & 20.3 & 32.1 & 39.8 \\
& \pm 6.14 & \pm 2.75 & \pm 3.48 \\
\hline $\mathrm{Cd}$ & 0.24 & 20.4 & 55.7 \\
& \pm 0.19 & \pm 6.84 & \pm 1.42 \\
\hline
\end{tabular}

After analysis of the heavy metal concentrations in the various solutions from the different experimental conditions it was found that different extraction times ( 0.5 and 1 hour) showed no significant differences in the heavy metal concentrations in the leachates. Extraction times of one hour are nevertheless recommendable.

Figure 1 shows the concentration values for Arsenic, Cadmium and Zinc in solution at different $\mathrm{pH}$ values (below $\mathrm{pH} 7$ extraction conditions with $\mathrm{HCl}$, above $\mathrm{pH} 7$ precipitation conditions with $\mathrm{NaOH}$ ). As expected, the highest concentrations of the heavy metals can be found at $\mathrm{pH} 4$.

For precipitation it can be seen for the case of Cadmium that a $\mathrm{pH}$ above 10 removes nearly to $100 \%$ all Cadmium from the solution. For Arsenic and Zinc already a $\mathrm{pH}$ of 8.5 leads to a complete precipitation of heavy metal hydroxides. An optimum $\mathrm{pH}$ for the investigated and limited heavy metals was therefore found to be around $\mathrm{pH} 10$ as at higher $\mathrm{pH}$ values (above around $\mathrm{pH}$ 12) small amounts of Zinc are again being mobilized.

\section{Conclusion}

The results of the study show that biomass fly ashes can be cleaned by acidic extraction with $\mathrm{HCl}$ at moderate $\mathrm{pH}$ values. Already at a $\mathrm{pH}$ value in the range of 4 to 5 good extraction results can be achieved, thereby limiting the consumption of the chemicals for the extraction and for the heavy metal precipitation.

It could further be found that at $\mathrm{pH}$ values around 10 the heavy metals can be removed from the leachate what enables their discharge.

\section{Outlook}

In a further studies the scale up of this cleaning procedure will be investigate.

\section{Acknowledgements}

The authors thank the biomass incineration plant for providing the biomass fly ashes.

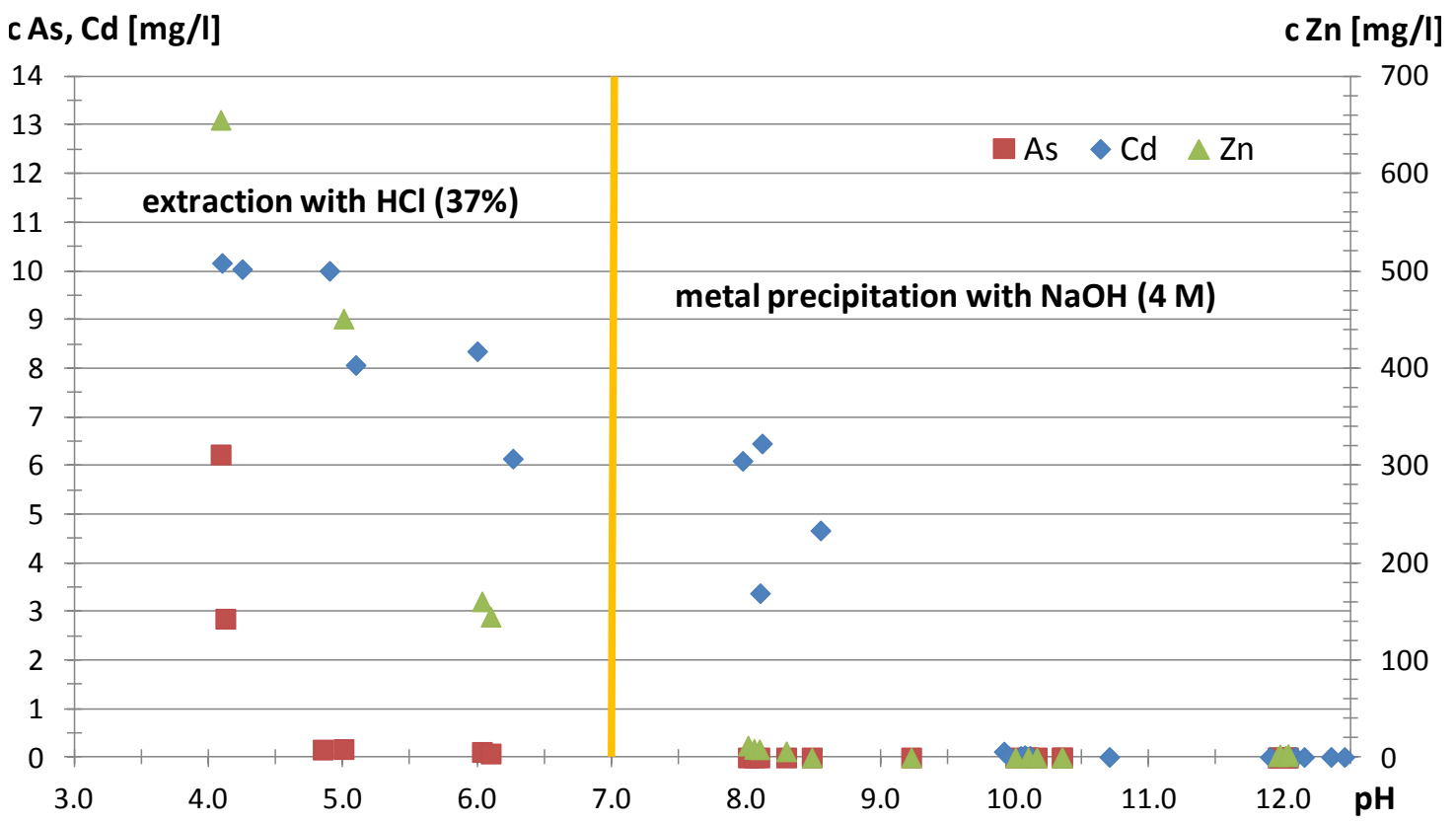

Fig. 1. Concentration of Arsenic, Cadmium and Zinc in solution after extraction with $\mathrm{HCl}$ at different $\mathrm{pH}$ values and precipitation with $\mathrm{NaOH}$ at different $\mathrm{pH}$ values. 


\section{References}

Austrian Ministry for Agriculture. The use of plant-ashes on crop- and farmland. recommendation 2011.

Bram S, De Ruyck J, Lavric D. Using biomass: A system perturbation analysis. Applied Energy 2009; 86:194-201

Chau J, Sowlati T, Skohansanj S, Preto F, Melin S, Bi X. Economic sensitivity of wood biomass utilization for greenhouse heating application. Applied Energy 2009; 86,5: 616-621

Kröppl M, Ceras-Arrese M, Lanzerstorfer C. Extraction of heavy metals from biomass fly ashes under acid conditions. Chemikertage, Linz, Austria. 2011
Kröppl M, Zeiner M, Lanzerstorfer C. Validation for the Determination of Extractable Metals in Ashes from Biomass Incinerators by ICP-OES. J. Chem. Chem. Eng. 2011; 5:495-501.

OÖ Biomasseverband, information from the head-office in Linz.

Pöykio R, Rönkkömäki H, Nurmesniemi H, Perämäki P, Popov K, Välimäki I, Tuomi T. Chemical and physical properties of cyclone fly ash from the grate-fired boiler incinerating forest residues at a small municipal district heating plant (6 MW). Journal of Hazardous Materials 2009; 162:1059-1064. 